\title{
Low intake of iodized salt and iodine containing supplements among pregnant women with apparently insufficient iodine status - time to change policy?
}

Shani R. Rosen ${ }^{1,2^{*}}$, Yaniv S. Ovadia ${ }^{2,3+}$, Eyal Y. Anteby ${ }^{2,4}$, Shlomo Fytlovich ${ }^{5}$, Dorit Aharoni ${ }^{5}$, Doron Zamir ${ }^{4,6}$, Dov Gefel ${ }^{1}$ and Simon Shenhav $2,4+$

\begin{abstract}
Background: lodine is an essential nutrient for human health throughout the life cycle, especially during early stages of intrauterine life and infancy, to ensure adequate neurocognitive development. The growing global reliance on desalinated iodine-diluted water raises the specter of increased iodine deficiency in several regions. The case of Israel may be instructive for exploring the link between iodine status and habitual iodine intake in the setting of extensive national reliance on desalinated water. The aim of this study was to explore the relationship between iodine intake, including iodized salt and iodine-containing supplements intake, and iodine status among pregnant women residing in a sub-district of Israel that is highly reliant on desalinated iodine-diluted water.
\end{abstract}

Methods: A total of 134 consecutive pregnant women were recruited on a voluntary basis from the obstetrics department of the Barzilai University Medical Center during 2018. Blood was drawn from participants to determine levels of serum thyrotropin (TSH), thyroid peroxidase antibodies (TPOAb), thyroglobulin antibodies (TgAb) and thyroglobulin (Tg). An iodine food frequency questionnaire (sIFFQ) was used to assess iodine intake from food, IS and ICS. A questionnaire was used to collect data on demographic and health characteristics.

Results: A total of 105 pregnant women without known or reported thyroid disease were included in the study. Elevated Tg values ( $\geq 13 \mu \mathrm{g} / \mathrm{L}$ ), were found among $67 \%$ of participants, indicating insufficient iodine status. The estimated iodine intake (median, mean \pm SD 189, $187 \pm 106 \mu \mathrm{g} / \mathrm{d}$ by sIFFQ) was lower than the levels recommended by the World Health Organization and the Institute of Medicine (250 vs. $220 \mu \mathrm{g} /$ day respectively). The prevalence of iodized salt intake and iodine containing supplement intake were 4 and $52 \%$ (respectively). Values of $\mathrm{Tg}>13 \mu \mathrm{g} / \mathrm{L}$ were inversely associated with compliance with World Health Organization and Institute of Medicine recommendations.

(Continued on next page)

\footnotetext{
* Correspondence: shani.rosen1@mail.huji.ac.il

${ }^{\dagger}$ Yaniv S. Ovadia and Simon Shenhav contributed equally to this work.

'School of Nutritional Science; Institute of Biochemistry, Food Science and Nutrition; Robert H. Smith Faculty of Agriculture, Food and Environment, The Hebrew University of Jerusalem, 76100 Rehovot, Israel

2Obstetrics and Gynecology Department, "Barzilai" University Medical Center

Ashkelon, Ashkelon, Israel

Full list of author information is available at the end of the article
}

(c) The Author(s). 2020 Open Access This article is distributed under the terms of the Creative Commons Attribution 4.0 International License (http://creativecommons.org/licenses/by/4.0/), which permits unrestricted use, distribution, and reproduction in any medium, provided you give appropriate credit to the original author(s) and the source, provide a link to the Creative Commons license, and indicate if changes were made. The Creative Commons Public Domain Dedication waiver (http://creativecommons.org/publicdomain/zero/1.0/) applies to the data made available in this article, unless otherwise stated. 
(Continued from previous page)

Conclusions: While the Israeli Ministry of Health has recommended the intake of iodized salt and iodine containing supplements, this is apparently insufficient for achieving optimal iodine status among Israeli pregnant women. The evidence of highly prevalent probable iodine deficiency in a sample of pregnant women suggests an urgent need for a national policy of iodized salt regulation, as well as guidelines to promote iodine containing supplements and adherence to them by caregivers. In addition, studies similar to this one should be undertaken in additional countries reliant on desalinated iodine-diluted water to further assess the impact of desalinization on maternal iodine status.

Keywords: Thyroglobulin, lodine, Desalination, Pregnancy, Thyroid, Nutrition

\section{Background}

Decades of public health research have established that iodine deficiency (ID) in pregnancy may impair neurological development of the offspring. Iodine is a crucial element for brain evolvement, especially during pregnancy when fetal brain development is very rapid. Notably, ID may result in compromised perinatal outcomes such as stillbirth, pre-eclampsia and cretinism. Additionally, ID is associated with compromised outcomes throughout life, such as altered IQ and cognition levels $[1,2]$. Globally, ID is the leading cause of preventable intellectual deficits [3]. In iodine sufficient areas, pregnant women (PW) may maintain stable total body iodine levels throughout pregnancy. However, in mild to moderate iodine deficient areas, total body iodine stores often decline throughout pregnancy. Moreover, iodine intake has a key role in thyroid function during pregnancy even in iodine sufficient areas [3, 4].

Inadequate iodine status is common among PW worldwide [5-7]. Out of 72 countries with data on iodine status based on median urinary iodine concentration (mUIC), approximately $54 \%$ are classified as ID, including countries in developed regions [5, 8]. The Israel National Iodine Survey (INIS) conducted in 2016, has shown that Israel is an ID country. Mild ID was found among a national representative sample of school-aged children $(n=$ 1023) and substantial iodine insufficiency was found in a representative sample of PW $(n=1074)$ [9]. Of PW spot UIC samples, 85\% were below the World Health Organization (WHO) adequacy range (150-249 $\mu \mathrm{g} / \mathrm{L}$ [10, $11])$, and the mUIC was $61 \mu \mathrm{g} / \mathrm{L}$. These data have placed Israel in the worst decile globally for iodine status [6]. The prevalence and degree of ID that was found in the INIS suggests that the population may not be able to fulfill its intellectual potential $[6,9]$. Thus, the ID found among PW indicates a serious public health concern in Israel.

In the wake of the INIS findings, the Israeli Ministry of Health $(\mathrm{MOH})$ promoted an iodine policy in early 2017, recommending replacement of regular table salt with iodized salt (IS), without increasing the amount of salt intake $[12,13]$. In late 2017, the MOH recommended intake of iodine containing supplements (ICS) with $150-250 \mu \mathrm{g} / \mathrm{d}$ iodine, starting 1 month prior to a planned pregnancy and continuing throughout lactation $[12,14,15]$. However, a mandatory national salt iodization policy has not yet been established and the $\mathrm{MOH}$ has only recommended IS intake on a voluntary basis $[9,13,16]$. Regarding ICS, the $\mathrm{MOH}$ recommendations have not been accompanied by specific and clear guidelines to promote relevant adherence by health care professionals $[9,12,14]$.

The reasons for the substantial ID found in Israeli PW are not fully understood. Recent data from the INIS suggest that national ID may be attributed, in part, to substantial reliance on iodine-diluted desalinated water (DIDW) [7, 9]. The INIS researchers also noted that IS availability and historical reporting of ICS intake was low [9]. However, the INIS was limited by the unavailability of medical records and detailed information regarding iodine intake. Therefore, information is needed on the local association between the iodine status of PW and habitual dietary iodine. Such information is important for policy makers in Israel and elsewhere, in order to develop an efficient and relevant iodine policy. Moreover, in light of the prevalence of ID among PW in both developing and developed regions around the world, exploring this link can contribute to the development of more definitive polices in Israel and globally.

The growing prevalence of water desalination globally [17] highlights the importance of data regarding the impact of habitual dietary iodine intake on iodine status $[7,17,18]$. Such information may be crucial in areas with DIDW reliance, which may diminish iodine intake $[7,19]$. Israel relies extensively on DIDW [7, 20]. The case of Israel's Ashkelon sub-district can be instructive, because stable estimates of DIDW exposure were available for this sub-district [19].

Accordingly, the aim of this study was to explore the relationship between iodine status and iodine-related dietary habits (including IS use and ICS intake), among PW from an area of Israel that is highly reliant on DIDW.

\section{Methods}

\section{Participants, settings and design}

The research proposal was approved by the Helsinki Committee at The Barzilai University Medical Center in 
Ashkelon (BUMCA). All PW who participated in this study provided written informed consent after the research protocols were explained in detail (Fig. 1).

The study took place at the Obstetrics and Gynecology Department of BUMCA. The BUMCA is located in the Ashkelon sub-district, a geographical area with extensive reliance on DIDW since 2011 [21]. Figure 2 presents a map showing the location of the city of Ashkelon (where the BUMCA is located), and the Ashkelon sub-district location and area.

The study was a cross-sectional study. Consecutive PW were prospectively enrolled to the study between May and December of 2018. Participants provided blood samples and responded to the study questionnaires, along with written informed consent. The exclusion criteria were: multiple pregnancies, intake of medications that interfere with thyroid function (e.g., amiodarone, glucocorticoids, lithium-containing), previously reported or documented TD, and any indications of an underlining TD (such as TSH $>10 \mathrm{mIU} / \mathrm{L}$, and positive thyroid antibodies: Thyroglobulin antibody (TgAb) values above $40 \mathrm{IU} / \mathrm{ml}$ and thyroid peroxidase (TPOAb); values above $35 \mathrm{IU} / \mathrm{ml}$ were considered positive as considered by previous studies [22]). Cases with positive TgAb values were not included because $\mathrm{TgAb}$ can interfere with serum thyroglobulin (Tg) analysis [23]. We considered iodine status to be sufficient $(\mathrm{Tg} \leq 13 \mu \mathrm{g} / \mathrm{L}$ ) or insufficient ( $\mathrm{Tg}>13 \mu \mathrm{g} / \mathrm{L})$ according to a recently suggested standard [22].

\section{Assays}

The Tg level was used as a biomarker of iodine status $[23,24]$. Blood samples were used for data on the levels of TSH, thyroid antibodies, TPO-ab, Tg-ab, Tg, free triiodothyronine (FT3), and free thyroxine (FT4), which were analyzed at the clinical biochemistry laboratory of the BUMCA, using electrochemiluminescence immunoassay on Modular Analytics E601 analyzer (Cobas, Roche Diagnostics GmbH, Mannheim, Germany). Reference ranges were $0.27-4.2 \mathrm{mU} / \mathrm{L}$ for TSH, 3.1-6.3 pmol/L for FT3, and $0.93-1.7 \mathrm{ng} / \mathrm{dL}$ for FT4.

\section{lodine intake assessment using semi-quantitative iodine food frequency questionnaire}

A previously used, semi-quantitative iodine food frequency questionnaire (sIFFQ) with a focus on iodine rich foods, designed for the Israeli adult population was used in order to assess habitual iodine intake as reported elsewhere [18]. Estimates of the iodine content of the foods consumed by study participants were derived from multiple sources: specific food items from the Department of Nutrition at the $\mathrm{MOH}$ (iodine composition

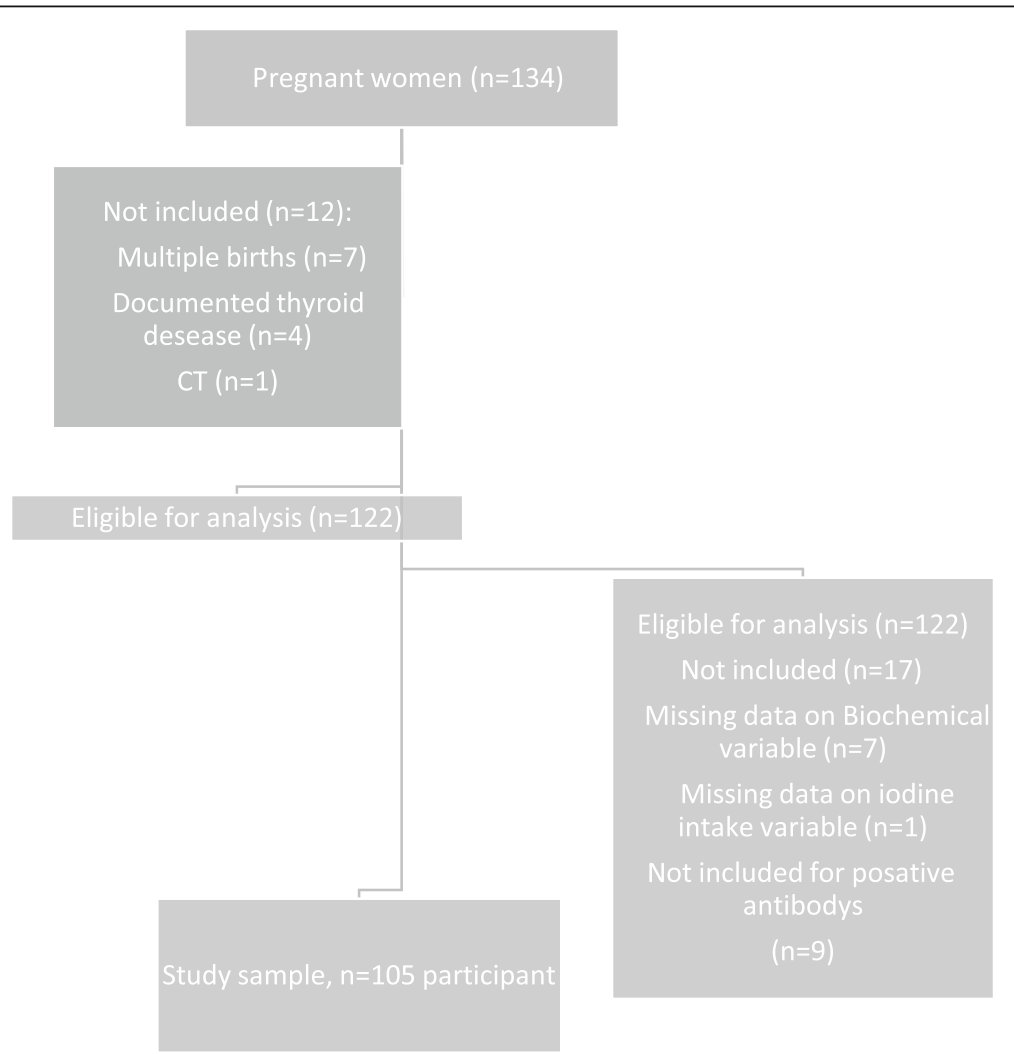

Fig. 1 Flow chart describing the screening process and the study sample generation. $C T=$ Computed tomography scan 


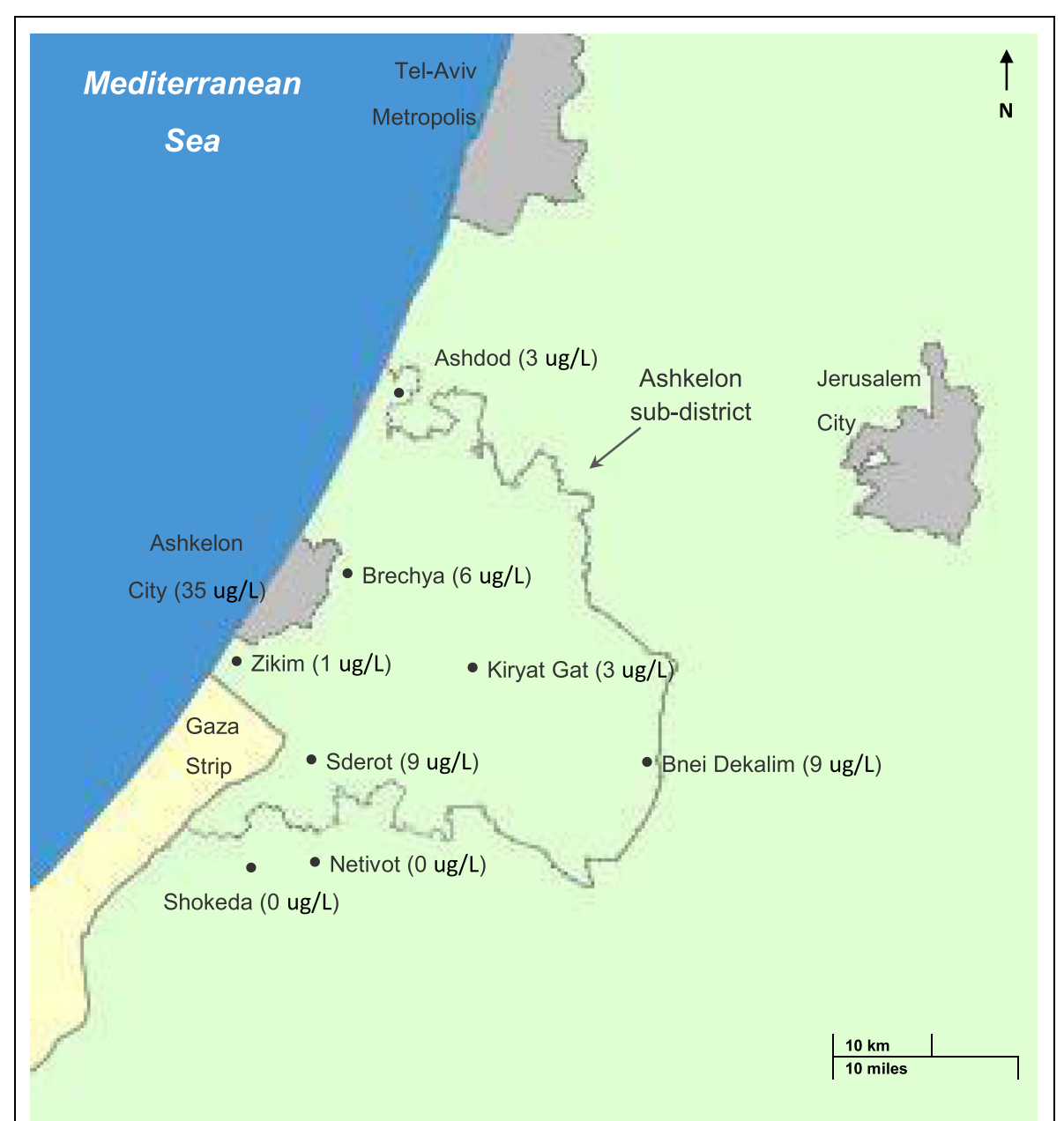

Fig. 2 Map of Israel's southern coastal area, showing Ashkelon sub-district and its surroundings. * Municipalities in which participants reported drinking unfiltered tap water are presented in bullet point and the estimated annual average of unfiltered tap water iodine concentrations (in ug/ $\mathrm{L})$ are shown in parentheses after the name of the locality: Ashkelon City $(35 \mu \mathrm{g} / \mathrm{L})$, Ashdod $(3 \mu \mathrm{g} / \mathrm{L})$, Kiryat Gat $(3 \mu \mathrm{g} / \mathrm{L})$, Sderot $(9 \mu \mathrm{g} / \mathrm{L})$, Bnei Dekalim $(9 \mu \mathrm{g} / \mathrm{L})$, Brechya $(6 \mu \mathrm{g} / \mathrm{L})$, Netivot $(0 \mu \mathrm{g} / \mathrm{L})$, Zikim $(1 \mu \mathrm{g} / \mathrm{L})$, Shokeda $(0 \mu \mathrm{g} / \mathrm{L})$

investigation in food by Dr. Eli Havivi 1989); fresh water fish from the Agricultural Service of Israel and the Israeli Fish Breeders Association (fresh water fish nutritional composition, 2012) [21, 25]. In brief, iodine intake was estimated for foods of marine origin (including fish and sea food), milk products (including milk, cheese and yogurt), water, and other significant sources of iodine [21].

In order to quantify the iodine intake from water, we used a quantitative model, which was previously used in Israel [19]. In this model, iodine from locally retailed bottled drinking water were considered negligible due to low content of iodine $(0-10 \mu \mathrm{g} / \mathrm{L}$ [26]). Filtered water was also excluded due to the high iodine variability of filtered water (in the range of $0-27 \mu \mathrm{g} / \mathrm{L}$ [19]). To model the contribution of drinking-water to daily iodine intake, we used geographic locality specific estimates of water iodide concentration. Content of iodine from water was calculated using geographic locality specific estimates of water iodide concentration. Mean iodide concentrations were estimated using data published by the $\mathrm{MOH}$ and the estimated annual proportion of DIDW supply reported by Mekorot Israel National Water Company for specific municipalities in the Ashkelon district (personal communication, Mr. Yuri Kasperuk, Israel's Southern Region Water Supply Engineer at Mekorot Israel National Water Co.). The extent of iodine intake via ICS was calculated using data from the manufacturers regarding the intake of the ICS, and self- reported detailed information from the study questionnaire regarding type of ICS, and the frequency and duration of ICS use.

\section{Additional data sources for variables related to iodine status}

Possible correlates of iodine status were examined using information obtained from medical records (regarding general medical background) as well as from the patient 
survey (regarding patient demographics, health, a history of thyroid disease, and weight gain during gestation). Correlation between biomarkers and the sIFFQ was used to provide better assessment regarding iodine status, as they are complementary measurements: $\mathrm{Tg}$ reflects Iodine intake of weeks to months, and sIFFQ reflects iodine intake during the previous year $[19,23]$. Spot urinary iodine concentration (UIC) is a common measure in population studies [27]. However, it was not considered suitable for this study, because of three reasons: (1) the high within-individual variability in UIC [28], (2) UIC indicates recent iodine intake (days), whereas $\mathrm{MOH}$ recommend achieving adequate iodine intake at least 1 month prior to conception and the study sample consists entirely of PW $[12,29]$, (3) The sample size of our study $(N=105)$ was not large enough $(N \geq 500)$ to level out the daytoday variation in iodine intake and urinary volume $[19,21]$.

\section{Statistical analysis}

Eligible data and samples were analyzed using IMB SPSS statistics software (version 25.0 Chicago IL USA). The $\mathrm{Tg}$ values were dichotomized to $\leq 13 \mu \mathrm{g} / \mathrm{L} \mathrm{Tg}>13 \mu \mathrm{g} / \mathrm{L}$ (sufficient vs. insufficient, respectively). Possible correlates of sufficient iodine status were examined using multiple logistic regression. Results were analyzed by pregnancy trimester, ICS intake, and locality. Maternal education level, smoking status, and iodine intake during gestation were included in the analysis. Correlation between biomarkers and the sIFFQ was analyzed using a Pearson correlation coefficient. Results are described as mean \pm SD. A two tailed $P$-value $<0.05$ was considered statistically significant.

\section{Results}

\section{Participants}

Of the 134 consecutive PW who originally enrolled in the study, 29 women were not included because they did not meet study eligibility criteria. Ultimately, 105 women were included in the analysis. Exclusions were due to multiple pregnancies $(n=7)$, documented thyroid disease $(n=4)$, Computed tomography scanning $(n=1)$, missing data on biochemical and questioner variables $(n=8)$ and thyroid antibody positivity $(n=9)$. This screening process and the study sample generation is described in Fig. 1.

Characteristics of participants are presented in Table 1. Mean \pm SD age was $31 \pm 7$ years, mean pre-conception BMI $25 \pm 6 \mathrm{~kg} / \mathrm{m}^{2} .18 \%$ of the participants were over age 35 and $76 \%$ were in their third trimester. $17 \%$ of participants were smokers at study entry, $46 \%$ had graduated college, $72 \%$ were born in Israel, and $45 \%$ had two or more children.

\section{Maternal iodine status assessment by Tg based on blood samples}

The median concentration of $\mathrm{Tg}$ cross-trimester was $17 \mu \mathrm{g} / \mathrm{L}$, (mean \pm SD $25 \pm 27 \mu \mathrm{g} / \mathrm{L}$ ), and $14 \%$ of $\mathrm{Tg}$ values were less than or equal to $40 \mu \mathrm{g} / \mathrm{L}$. Median and mean \pm SD concentrations were, TSH $(n=104,1.6,1.6 \pm 0.8$ $\mu \mathrm{IU} / \mathrm{mL})$, FT3 $(n=102,4.2,4.2 \pm 0.6 \mathrm{pmol} / \mathrm{L})$ and FT4 $(n=101,1,1 \pm 0.1 \mathrm{ng} / \mathrm{dL})$. Iodine status sufficiency was assessed using two cut-off values of Tg. Of the participants, $67 \%$ did not meet the $\mathrm{Tg} \leq 13 \mu \mathrm{g} / \mathrm{L}$ standard, while $14 \%$ did not meet the $\mathrm{Tg}>40 \mu \mathrm{g} / \mathrm{L}$ standard. Median $\mathrm{Tg}$ was $17 \mu \mathrm{g} / \mathrm{L}$. These parameters did not differ significantly by week of pregnancy, intake of goitrogenic foods, or smoking status (data not presented). They did vary significantly by iodine intake for $\mathrm{Tg} \leq 13 \mu \mathrm{g} / \mathrm{L}$ and for $\mathrm{Tg}>40 \mu \mathrm{g} / \mathrm{L}(p<0.05, p<0.001$, respectively $)$ and by ICS intake for $\mathrm{Tg}>40 \mu \mathrm{g} / \mathrm{L}(p<0.001)$.

\section{Habitual dietary iodine intake assessment by sIFFQ}

The median iodine intake from food and ICS was $189 \mu \mathrm{g} / \mathrm{d}$ (mean $187 \pm 106 \mu \mathrm{g} / \mathrm{d}$ ), whereas the median iodine intake from food alone was $80 \mu \mathrm{g} / \mathrm{d}$ (mean $96 \pm$ $64 \mu \mathrm{g} / \mathrm{d}$ ) and from food and water was $94 \mu \mathrm{g} / \mathrm{d}$ (mean $106 \pm 66 \mu \mathrm{g} / \mathrm{d}$ ). Full distribution of the study sample's estimated daily iodine intake $(\mu \mathrm{g} / \mathrm{d})$ according to sIFFQ $(n=105)$ is presented in Fig. 3. Intake of IS was reported by $4 \%$ of participants $(n=4)$. The proportion of participants reporting intake of ICS during gestation was 52\% $(n=55)$, mostly starting intake by the end of the first trimester (mean week 8 of gestation, median week 8 of gestation). The proportion of participants that reported intake of ICS prior to pregnancy was $11 \%(n=80)$. Almost half $(48 \%)$ of the participants reported intake of unfiltered tap water on a daily basis, with a mean value of $0.5 \mathrm{l} /$ day. Notably, $14 \%$ of PW reported intake of at least 1 liter/day. Among participants who reported drinking tap water, the average contribution of tap water to the daily mean iodine intake was $19 \mu \mathrm{g} / \mathrm{d}$ - $9 \%$ of the Institute Of Medicine (IOM) recommendation for daily adequate iodine intake - 220 ug [30]. Annual average iodine concentrations (in ug/L) of unfiltered tap water are shown in Fig. 2 for localities which had respondents who reported drinking unfiltered tap water.

As indicated in Table 2, in total, $41 \%$ of participants complied with IOM iodine intake recommendations. Compliance with recommendations was associated with a report of ICS intake $(p<0.001)$. Among the participants that reported intake of ICS, $71 \%$ complied with recommendations. Among the participants that reported no intake of ICS, $8 \%$ complied with recommendations. In total, $31 \%$ of participants complied with WHO iodine intake recommendations. Compliance with recommendations was associated with a report of ICS intake $(p<0.001)$. Among the participants that reported intake of ICS, 55\% 
Table 1 Socio-demographic characteristics of the study sample

\begin{tabular}{|c|c|c|c|c|}
\hline & Number & Percent & Mean & Median \\
\hline \multicolumn{5}{|l|}{ Total $n=105$} \\
\hline Maternal age (years) & 95 & 100 & $31 \pm 5$ & 31 \\
\hline Up to 25 & 15 & 14 & & \\
\hline $26-35$ & 71 & 75 & & \\
\hline Over 35 & 19 & 18 & & \\
\hline Gestational age at study entry, weeks & 95 & 100 & $31 \pm 7$ & 32 \\
\hline First trimester & 4 & 4 & & \\
\hline Second trimester & 19 & 20 & & \\
\hline Third trimester & 72 & 76 & & \\
\hline Smoking status & 105 & NA & & \\
\hline Smoked before pregnancy & 34 & 34 & & \\
\hline Smoking at study entry & 18 & 17 & & \\
\hline No smoking & 66 & 66 & & \\
\hline Education & 105 & 100 & NA & NA \\
\hline Graduated college & 48 & 46 & & \\
\hline Other & 57 & 54 & & \\
\hline Country of birth & 105 & 100 & NA & NA \\
\hline Israel & 72 & 72 & & \\
\hline Other & 28 & 28 & & \\
\hline Number of children & 100 & 100 & $1.58 \pm 1.57$ & 1 \\
\hline None & 28 & 29 & & \\
\hline One & 27 & 28 & & \\
\hline Two or more & 45 & 45 & & \\
\hline Preconception BMl, kg/m2 & 63 & 100 & $25 \pm 6$ & 24 \\
\hline Underweight (less than 18.5) & 4 & 6 & & \\
\hline Normal weight (18.5-24.9) & 31 & 49 & & \\
\hline Overweight (24.9-29.9) & 20 & 32 & & \\
\hline Obese (30-34.9) & 5 & 8 & & \\
\hline Extremely obese (35 and higher) & 3 & 5 & & \\
\hline
\end{tabular}

$N A$ not available, $B M I$ body mass index

complied with the recommendations of IOM. Of the participants who did not report ICS intake, $6 \%$ complied with IOM recommendations [30]. The difference between the groups is statistically significant $(p<0.001)$.

As indicated in Fig. 4, among participants who complied with IOM iodine intake recommendations [30], 91\% reported ICS intake. The proportion of reported ICS intake was $26 \%$ among participants who did not meet the IOM recommendation [30] $(p<0.001)$. These proportions were $91 \%$ and $35 \%$ (respectively) when compared to the WHO standard [11] $(p<0.001)$.

The relationship between iodine status and iodine intake As indicated in Table 3, Tg concentrations were correlated with intake of iodine from food and ICS. In total, $67 \%$ of participants had a Tg value of over $13 \mu \mathrm{g} / \mathrm{L}$. This figure was $74 \%$ among participants who did not meet the IOM standard for iodine intake $(220 \mu \mathrm{g} / \mathrm{d})$ [30], and $56 \%$ among participants who did meet the IOM standard. The difference between the groups is statistically significant $(p<0.05)$.

In total, $14 \%$ of participants had a $\mathrm{Tg}$ value of over $40 \mu \mathrm{g} / \mathrm{L}$. This figure was $21 \%$ among participants who did not meet the IOM standard for iodine intake $(220 \mu \mathrm{g} / \mathrm{d})$ [30], and 5\% among participants who complied with IOM recommendations. The difference between the groups is statistically significant $(p<0.05)$.

\section{Discussion}

Summary of key findings

Our study found that $14 \%$ of the participants had a $\mathrm{Tg}$ value of over $40 \mu \mathrm{g} / \mathrm{L}$. This can be compared with a 


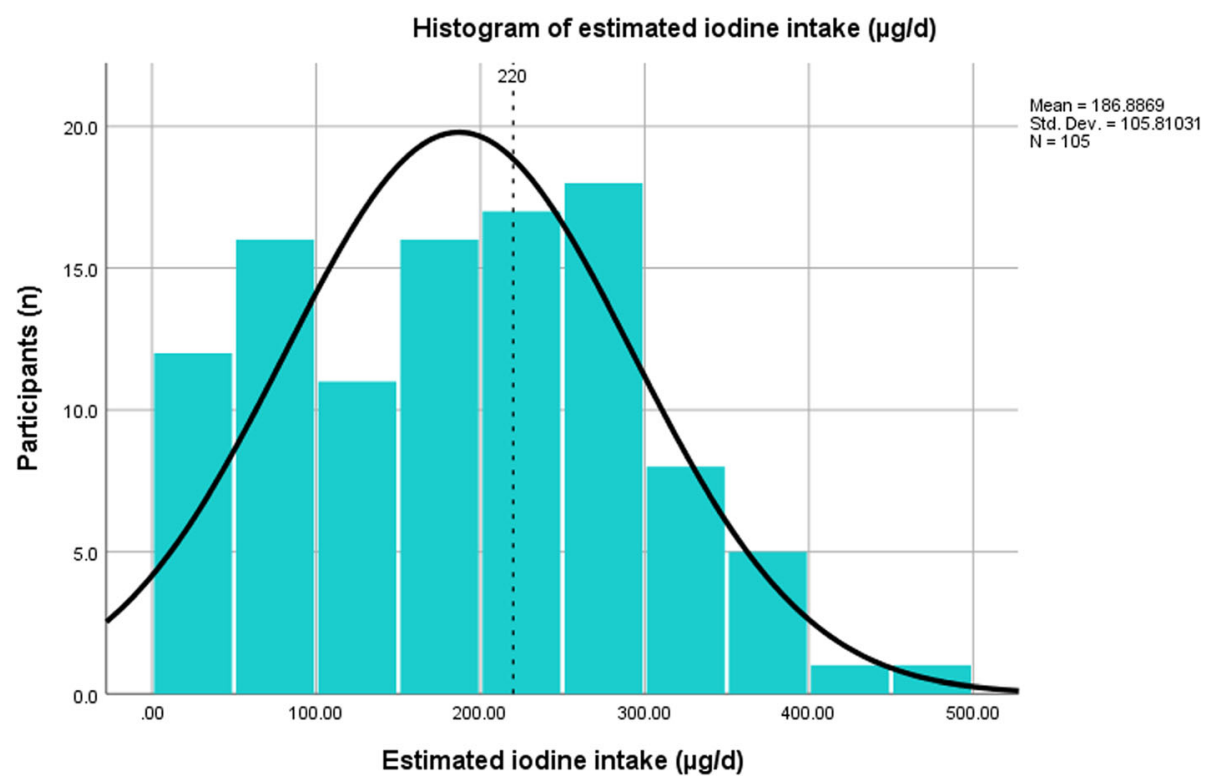

Fig. 3 Distribution of estimated daily iodine intake $(\mu \mathrm{g} / \mathrm{d})$ of the study sample according to sIFFQ $(n=105)$. Note: Reference line represents IOM and DRI guidelines for iodine intake $(220 \mu \mathrm{g} / \mathrm{d})$ from food, IS and ICS. $\mathrm{gg} / \mathrm{d}$ = micrograms per day; sIFFQ= semi-quantitative iodine food frequency questionnaire; $I O M=$ Institute of Medicine; DRI = dietary reference intake; IS = iodized salt; ICS = iodine-containing supplements; $\mathrm{WHO}=$ World Health Organization

proposed standard which suggests that a population is iodine sufficient only if less than $3 \%$ of the population has $\mathrm{Tg}$ values greater than $40 \mu \mathrm{g} / \mathrm{L}$ (proposed indicator for population iodine status adequacy) [22, 31]. It is also noteworthy that $67 \%$ of the participants in the study sample had a $\mathrm{Tg}$ value of over $13 \mu \mathrm{g} / \mathrm{L}$, as another proposed standard is that a population is iodine sufficient only if the median $\mathrm{Tg}$ is less than $13 \mu \mathrm{g} / \mathrm{L}[22,31]$. As for iodine intake, $41 \%$ of participants met the IOM standard for iodine intake [30]. In our sample, a Tg level over $40 \mu \mathrm{g} / \mathrm{L}$ was inversely associated with meeting IOM iodine intake recommendations $(p<0.05)$ and with intake of ICS $(p<0.001)$. Furthermore, a Tg level of over $13 \mu \mathrm{g} / \mathrm{L}$ was inversely associated with achieving IOM iodine intake recommendations $(p<0.05)$.

The study also found that the percent of participants who reported intake of IS during gestation was $4 \%$, similar to the low rate of $3 \%$ of locally retailed IS (almost all of which is produced in Israel [16]). Most locally retailed IS contains approximately $30 \mathrm{mg} / \mathrm{Kg}$., so that intake of a teaspoon (5 g) of IS each day is sufficient for the general population. However, a teaspoon a day would supply only $68 \%$ of the Dietary Reference Intakes (DRI) for PW (DRI, IOM: $220 \mathrm{mg} /$ day [12, 16, 32]). Thus, serious consideration needs to be given to ways to increase the availability and intake of IS, particularly in regions around the globe that are reliant on DIDW.

The Israeli $\mathrm{MOH}$ published updated guidelines in 2017 recommending intake of $150-250,150-250 \mu \mathrm{g} / \mathrm{d}$ of iodine, starting at least 1 month prior to a planned pregnancy. This study found, however, that only $52 \%$ of participants reported intake of ICS during gestation. Moreover, initiation of ICS intake was on average at week 8 of gestation, with only $11 \%$ of participants reporting initiation of ICS prior to pregnancy. Thus, this study found low adherence to the ICS intake recommended by the $\mathrm{MOH}$. The low prevalence of ICS intake and the late time of initiation may be due in part to a lag in updating the Israeli gynecology guidelines with specific and clear new guidance on ICS. The $\mathrm{MOH}$

Table 2 Percent of PW meeting iodine intake standards stratified by the taking of supplements

\begin{tabular}{llll}
\hline & $\mathrm{N}$ & $\geq 220 \mu \mathrm{g}$ iodine/day (IOM standard) & $\geq 250 \mu \mathrm{g}$ iodine/day (WHO standard) \\
\hline Total & $\mathbf{1 0 5}$ & $\mathbf{4 1 \%}$ & $\mathbf{3 1 \%}$ \\
Taking supplements containing iodine & 55 & $71 \%$ & $55 \%$ \\
Not taking supplements containing iodine & 50 & $8 \%$ & $6 \%$ \\
$P$ value & & .00 & .00 \\
\hline
\end{tabular}

IOM [11, 30]

PW Pregnant Women, IOM Institiue of Medicien, WHO World Health Organization 


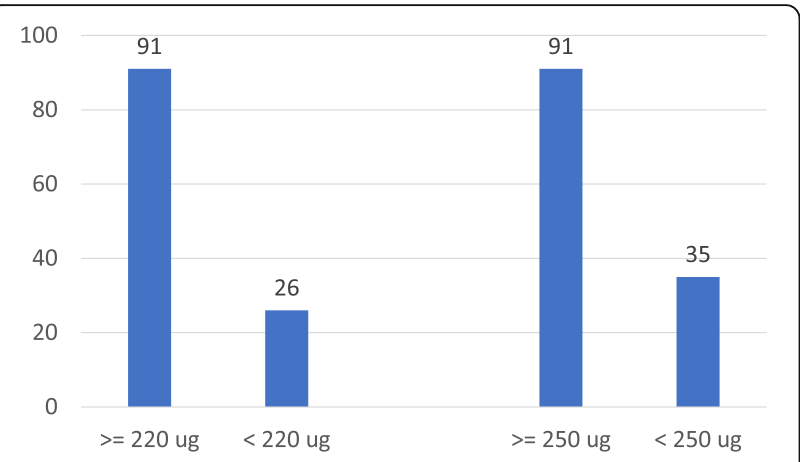

Fig. 4 Percent of PW reporting ICS among the study sample, stratified by level of iodine intake (as assessed by sIFFQ). PW = Pregnant women; SIFFQ = semi-quantitative iodine food frequency questionnaire

should encourage the gynecology profession to promptly update the profession's nutrition guidelines. In addition, the $\mathrm{MOH}$ should communicate the importance of adequate iodine intake during pregnancy to the general public, the health plans, primary care physicians, and other health professionals.

\section{Unique aspects of this study}

This is the first study of the iodine status among a sample of Israeli PW residing in an area with extensive reliance on DIDW, using $\mathrm{Tg}$ as an iodine probable status indicator. There is no well-established biomarker for measuring iodine status in an individual, but Tg may be a functional biomarker of iodine status in mild-moderate ID populations [23, 27]. Mild-moderate ID during pregnancy stresses the thyroid gland. An increase in Tg during pregnancy suggests that thyroid gland volume is increasing accordingly [23]. Tg is considered a more sensitive indicator of iodine repletion than TSH since it declines more rapidly with iodine repletion [23]. The $\mathrm{Tg}$ and the sIFFQ are complementary assessment methods

Table 3 The relationship between Tg cut-off values and iodine intake in the study sample

\begin{tabular}{|c|c|c|c|}
\hline & $\mathrm{N}$ & $\mathrm{Tg}>13 \mu \mathrm{g} / \mathrm{d}$ & $\mathrm{Tg}>40 \mu \mathrm{g} / \mathrm{d}$ \\
\hline lodine intake & 105 & & \\
\hline$\geq 220 \mu \mathrm{g} / \mathrm{d}$ & 43 & $56 \%$ & $5 \%$ \\
\hline$<220 \mu \mathrm{g} / \mathrm{d}$ & 62 & $74 \%$ & $21 \%$ \\
\hline$P$ value & & .049 & .019 \\
\hline \multicolumn{4}{|c|}{ Intake of iodine containing supplements } \\
\hline Yes & 55 & $60 \%$ & $4 \%$ \\
\hline No & 50 & $74 \%$ & $26 \%$ \\
\hline$P$ value & & 0.12 & 0.001 \\
\hline
\end{tabular}

IOM standard for iodine intake $(220 \mu \mathrm{g} / \mathrm{d},[30])$, includes intake from both food and supplements

Tg Serum thyroglobulin, IOM Institute Of Medicine of iodine status [23], therefore in this study we also used the sIFFQ method, which has been established as an accurate method for assessing long term usual intakes of foods as well as placing participants into levels of intake. The sIFFQ used in this study is estimated to capture 94-97\% of the iodine intake [21].

\section{The desalination context}

The growing shortage of fresh water has become a global problem $[17,18]$. As part of the solution, sea water is being desalinated in an increasing number of countries, supplying approximately 118 cubic meters a day for more than 300 million people globally $[7,17,18]$. Israel is a pioneer in seawater desalination, where $80 \%$ of the drinking water comes from DIDW (based on accumulated annual reported proportion [7, 19, 20]).

Desalination is an important means to address the global water scarcity [18]. However, it can inadvertently present a new challenge in regions where drinking water has provided a substantial portion of the iodine needed to achieve the recommended dietary allowance (RDA) for iodine [7, 19]. Reliance on DIDW places PW at an increased risk for ID [7, 9]. Accordingly, knowledge regarding the iodine status of PW, and factors influencing that status, is important for designing intervention to address this problem - both in Israel and globally [7].

\section{The relationship between this study and earlier Israeli studies}

Along with findings of geographic variation in iodine concentrations of local water sources, ID has been reported in Israel for decades [9, 33, 34]. As reported by Rosenthal et al., changes over time in the source of water, and its iodine content, have had significant impact on goiter incidence in the northern part of Israel [33]. Our findings are consistent with, and may help explain, the findings of the INIS regarding low iodine status among PW [7, 9]. In the INIS, spot urine samples of 1074 PW were collected and mUIC was examined by regions, religious sectors, and pregnancy trimesters. The INIS was the first national study to reveal that ID is a serious national public-health concern, with $85 \%$ of PW UIC samples resulting in values below the adequacy range $(150-249 \mu \mathrm{g} / \mathrm{l})$, and a mUIC of $61 \mu \mathrm{g} / \mathrm{l}$ (interquartile range (IQR) 36-97 l $\mu \mathrm{g} / \mathrm{d})$. Furthermore, a recent report from 2016, $(N=50)$, where most of the sample consisted of apparently healthy childbearing aged women from the Ashkelon sub-district, showed low iodine status, based on the high median $\mathrm{Tg}(21 \mathrm{ng} / \mathrm{mL})$, and prevalent elevated $\mathrm{Tg}$ values ( $\mathrm{Tg} \geq 10 \mathrm{ng} / \mathrm{mL}, 76 \%$ ). The study also found a median iodine intake below the recommended daily intake (RDA) (99 vs $150 \mu \mathrm{g} /$ day respectively [35]). 
The researchers who conducted the INIS indicated several reasons for insufficient iodine status, such as, reliance on IDDW, low IS availability and historical low reporting of ICS intake [9]. Our study suggests that the findings found in previous studies in Israel $[7,9]$ may indeed be due in part to the reasons hypothesized in the INIS, with low levels of ICS and IS intake. The iodine status assessment methods used in our study complement those used in the INIS. The INIS study used mUIC and our study used $\mathrm{Tg}$ and sIFFQ. An important strength of the INIS is that it is national in scope. Complementary strengths of our study are the availability of medical records and habitual dietary iodine intake information.

\section{Relevant studies from other countries}

A review from 2014 examined the $\mathrm{Tg}$ values of iodine deficient PW, and found that the majority of studies reported median $\mathrm{Tg}$ values exceeding $13 \mu \mathrm{g} / \mathrm{L}$ [22]. A recent study from the UK $(n=230)$ found median $\mathrm{Tg}$ values of $21,19,23 \mu \mathrm{g} / \mathrm{d}$ in the first, second and third trimesters respectively [23]. Furthermore, $18 \%$ of PW had $\mathrm{Tg}$ values greater than $40 \mu \mathrm{g} / \mathrm{L}$, well exceeding the standard of $3 \%$ proposed by Zimmerman et al. [31]. The Tg values were higher in the iodine deficient group, where ID was classified based on a UIC level of less than $150 \mu \mathrm{g} / \mathrm{L}$. No association was found between TSH values and ID. Iodine intake from milk (as estimated by a food frequency questionnaire) was inversely associated with $\mathrm{Tg}$ values [23]. A study from 2018 by Mioto et al. conducted in Brazil $(n=273)$ examined PW from an iodine sufficient area. Those PW had a median $\mathrm{Tg}$ of $11.2 \mu \mathrm{g} / \mathrm{L}$ and only $3.3 \%$ had a value exceeding $40 \mu \mathrm{g} / \mathrm{L}$; mUIC was $140 \mu \mathrm{g} / \mathrm{L}$ [4]. The extent of iodine insufficiency found in our study (a median $\mathrm{Tg}$ concentration of $17 \mu \mathrm{g} / \mathrm{L}$ and $14 \%$ exceeding $40 \mu \mathrm{g} / \mathrm{L}$ ) was more moderate than what was found in the 2014 review, and more serious than what was found in the Mioto et al. study.

\section{Study limitations}

Our study had several limitations. First, the crosssectional design of the study limits our knowledge on the intra-individual thyroid function changes throughout pregnancy as well as in concordance with iodine availability. Second, the sIFFQ method is limited in its capacity to provide an exact estimation of food intake, although it is accurate for assessing long term usual intakes of foods as well as placing participants into levels of intake. Third, the sample size of this study was relatively small, thereby limiting the extent and reliability of sub-group comparisons. Furthermore, the generalizability of the study's findings is limited by the lack of a sample from a site less dependent on desalination. Finally, the connivance sample consisted of volunteers attending the Obstetrics and Gynecology department of BUMCA; therefore the sample might not reflect the overall PW population in the Ashkelon sub-district. To limit the potential bias, we did not included PW with health conditions known to affect iodine status, such as thyroid dysfunction and PW who used medications that are known to effect iodine status or thyroid function.

\section{Avenues for further research}

Our study showed prevalent iodine insufficiency $(67 \%$ of Tg values $\geq 13 \mu \mathrm{g} / \mathrm{L}$ ) among PW residing within and near the Ashkelon sub-district, which is highly reliant on DIDW [21]. However, additional research is needed in regions with different levels of reliance on DIDW to establish a fuller understanding of the relationship between desalination and ID [7, 18].

Research should also be carried out on a general community sample. Finally, it will be important to assess how reliance on DIDW affects the prevalence of neonatal hypothyroidism and the extent to which ICS intake as well as whether preconception initiation of ICS can reduce that prevalence. In the current study, along with relatively high $\mathrm{Tg}$ values, iodine intake was low compared to the recommendations of the WHO [11] and the IOM [30]. This may be due, in part, to negligible use of IS (used by only $4 \%$ of the PW) and low use of ICS (taken by $52 \%$ of the PW).

\section{Policy implications}

Fortification and supplementation have a long tradition in public health practice [36-38]. Fortification of basic foods is the best way to prevent silent malnutrition $[36,38]$. Around the world, iodine fortification has been practiced for nearly a century [36, 39]. In Israel, the $\mathrm{MOH}$ has debated the development of policy and the implementation of practical guidelines for decades [37], with gradual progress with partial salt iodization [40]. In 2011 the Israeli National Nutrition Committee 2020 published recommendations regarding fortification of salt with iodine [41]. In early 2017, the $\mathrm{MOH}$ published guidelines for the general public encouraging voluntary use of IS [13]. Importantly, it is currently unclear whether fortification alone can provide adequate iodine intake during pregnancy and lactation [39, 42, 43], and the range of appropriate iodine levels is narrow. Moreover, if a country moves ahead with a Universal Salt Iodization Program, then its ICS recommendations for PW must be carefully calibrated so that women of child bearing age and PW get the appropriate amount of iodine - neither too little nor too much [39, 43-48]. Intake of both IS and ICS, together with other iodine rich food 
sources, may potentially lead to excessive iodine intake $[16,30,39,49]^{1}$.

We strongly suggest that the $\mathrm{MOH}$ consider the following stesp [36, 37, 42]:

- Adopt WHO guidelines for iodization of salt and the development of a national universal salt iodization program, in coordination with the ICS recommendations for PW [38, 39, 44-47, 50];

- Encourage cooperative industry engagement using regulation and financial incentives [43];

- Initiate a professional advisory board composed of clinicians, public policy makers and industry representatives;

- Promote ICS adherence and knowledge of dietary iodine sources by caregivers and possibly by health maintenance organizations;

- Promote awareness (among both professionals and pregnant women themselves) of the importance of adequate iodine intake during pregnancy; accelerating public health information campaign and professional education initiatives;

- Institute appropriate regulations and a monitoring program to ensure adequate and safe fortification and supplementation [37].

\section{Conclusions}

In conclusion, the $\mathrm{MOH}$ policy currently falls short of achieving sufficient iodine status in Israeli PW, regardless of efforts to increase iodine intake in the public. This is true in particular regarding voluntary IS intake by the general population as well as voluntary ICS intake among PW, as demonstrated in this study. Thus, effective strategies to improve iodine status are warranted. Specifically, this study suggests an urgent need for governmental leadership to address ID among PW, and the broader issue of iodine deficiency also needs to be addressed. We recommend implementing a mandatory iodine fortification program in Israel, including a wellmonitored IS program in keeping with WHO standards, as well as actively promoting guidelines for ICS adherence by caregivers throughout the Israeli health system. In order to ensure optimal iodine intake among PW, the guidelines should consider total iodine intake from multiple sources.

\footnotetext{
${ }^{1}$ For example, daily intake of 1 teaspoon of IS with $30 \mathrm{mg} / \mathrm{Kg}(150 \mu \mathrm{g})$, 1 tablet of ICS with $220 \mu$ g, as well as a single $240 \mathrm{ml}$ glass of cow milk with iodine concentration of $30 \mu \mathrm{g} / 100 \mathrm{~g}(\sim 70 \mu \mathrm{g})$ in addition to 1 whole egg with iodine concentration of $40 \mu \mathrm{g} / 100 \mathrm{~g}(20 \mu \mathrm{g})$ and a $200 \mathrm{~g}$ Salmon fish fillet $(\sim 300 \mu \mathrm{g})$ or seaweed products with broad range of $11-6118 \mu \mathrm{g} / \mathrm{g}$ may exceed both the European or IOM tolerable upper limit of 600 or even $1100 \mu \mathrm{g} / \mathrm{d}$ (respectively).
}

\section{Abbreviations}

BMI: Body mass index; BUMCA: Barzilai University Medical Center in Ashkelon; DIDW: Desalinated iodine-diluted water; ICS: lodine-containing supplements; ID: lodine deficiency; INIS: Israel National lodine Study; IOM: Institute of Medicine; IS: lodized salt; PW: Pregnant women; SD: Standard deviation; sIFFQ: semi-iodine food frequency questionnaire; Tg: Thyroglobulin; TgAb: Thyroglobulin antibodies; TPOAb: Thyroid peroxidase antibodies; TSH: Thyrotropin; Ug/L: micrograms per liter; WHO: World Health Organization; $\mu \mathrm{g} / \mathrm{d}$ : micrograms per day

\section{Acknowledgements \\ The authors are indebted to all of the participants who volunteered for this study; We wish to thank Dr. Bruce Rosen for his guidance on scientific writing; Mrs. Nirit Nagar from the BUMCA Department of Internal Medicine " $\mathrm{C}$ " and Mrs. Ruhama Kremer of the BUMCA Department of Obstetrics and Gynecology for their assistance with the administration of the study at BUMCA; Mrs. Mazal Malca Elharar from BUMCA Department of Obstetrics and Gynecology for her assistance with the blood samples collection; Mr. Gorion Ghatani and Dr. Avi Rimler from the BUMCA clinical biochemistry laboratory for their assistance with the laboratory data and Mr. Yuri Kasperuk, Israel's Southern Region Water Supply Engineer at Mekorot Israel National Water Co., for information regarding the proportion of desalinated water supplied to specific municipalities in the Ashkelon sub-sistrict and its surroundings.}

\section{Authors' contributions}

SRR administered the dietary interviews and questionnaires, supervised the collection of the blood samples, analyzed the data, and prepared the first draft of the manuscript. YSO, EYA, DZ and DG initiated and designed the study. SRR, YSO, DZ, and DG obtained the ethical approval. EYA, DG, and SS recruited participants and obtained informed consent. YSO and DG had a significant role in data analysis and preparation of the manuscript. SF and DA performed the assays. All authors provided comments on the initial draft and approved the final manuscript.

\section{Funding}

This study was funded in part by a BUMCA intramural fund.

\section{Availability of data and materials}

Please contact the lead author for data requests.

Ethics approval and consent to participate

The research proposal was approved by the Helsinki Committee at BUMCA. All PW who participated in this study provided written informed consent after the research protocols were explained in detail.

\section{Consent for publication}

NA

\section{Competing interests}

The authors declare that they have no competing interests.

\section{Author details}

${ }^{1}$ School of Nutritional Science; Institute of Biochemistry, Food Science and Nutrition; Robert H. Smith Faculty of Agriculture, Food and Environment, The Hebrew University of Jerusalem, 76100 Rehovot, Israel. ${ }^{2}$ Obstetrics and Gynecology Department, "Barzilai" University Medical Center Ashkelon, Ashkelon, Israel. ${ }^{3}$ Foreign studies department; Robert H. Smith Faculty of Agriculture, Food and Environment, The Hebrew University of Jerusalem, Jerusalem, Israel. ${ }^{4}$ Faculty of Health Sciences, Ben-Gurion University of Negev, Ashkelon, Israel. ${ }^{5}$ Laboratory of Clinical Biochemistry, Barzilai University Medical Center Ashkelon, Ashkelon, Israel. " Internal Medicine Department, Barzilai University Medical Center Ashkelon, Ashkelon, Israel.

Received: 27 August 2019 Accepted: 18 February 2020

Published online: 30 March 2020

\section{References}

1. Velasco I, Bath S, Rayman M. lodine as essential nutrient during the first 1000 days of life. Nutrients. 2018;10(3):290.

2. Gowachirapant S, Jaiswal N, Melse-Boonstra A, et al. Effect of iodine supplementation in pregnant women on child neurodevelopment: a 
randomised, double-blind, placebo-controlled trial. Lancet Diabetes Endocrinol. 2017:5(11):853-63.

3. Alexander EK, Pearce EN, Brent GA, et al. 2017 guidelines of the American Thyroid Association for the diagnosis and management of thyroid disease during pregnancy and the postpartum. Thyroid. 2017; 27(3):315-89.

4. Mioto VCB, Monteiro ACCNG, de Camargo RYA, et al. High prevalence of iodine deficiency in pregnant women living in adequate iodine area. Endocr Connect. 2018;7(5):762-7.

5. Bath SC. The effect of iodine deficiency during pregnancy on child development. Proc Nutr Soc. 2019;78(2):150-60,

6. Network IG. Global scorecard of iodine nutrition in 2017 in the general population and in pregnant women (PW). Zurich: IGN; 2017.

7. Boroje IJ, Koren G, Lamm SH. Sea water desalination: a newly discovered cause of iodine deficiency. Birth Defects Res. 2018;110(12):971-2.

8. Gizak M, Gorstein J, Andersson M. Epidemiology of iodine deficiency in iodine deficiency disorders and their elimination; Pearce, EN, Ed. Cham: Springer; 2017

9. Ovadia YS, Arbelle JE, Gefel D, et al. First Israeli national iodine survey demonstrates iodine deficiency among school-aged children and pregnant women. Thyroid. 2017;27(8):1083-91.

10. Organization WH. Urinary iodine concentrations for determining iodine status in populations: world Health organizations, 2013.

11. WHO U. ICCIDD. Assessment of the iodine deficiency disorders and monitoring their elimination. Geneva: World Health Organization; 2007. Report no. Food Nutr Res 2015;59:29829.

12. Health SolMo. Proper Nutrition During Pregnancy: iodine nutrition: State of Israel Ministry of Health; 2018. https://www.health.gov.l//English/Topics/ FoodAndNutrition/Nutrition/Adequate_nutrition/Pages/iodine.aspx: [Available from: https://www.health.gov.l//English/Topics/FoodAndNutrition/ Nutrition/Adequate_nutrition/Pages/iodine.aspx Accessed 8.18.2019 2019.

13. $\mathrm{MOH}$. FoodAndNutritio /Adequate nutrition iodine: $\mathrm{MOH}$; [Available from: https://www.health.gov.il/English/Topics/FoodAndNutrition/Nutrition/ Adequate_nutrition/Pages/iodine.aspx Accessed 17 Nov 2019.

14. Health SolMo. Proper nutrition during pregnancy: special nutritional ingredients and altering their consumption to meet requirements during the period of pregnancy. Jerusalem: State of Israel Ministry of Health; 2017

15. Health SolMo. Services PHSFC. Terms and conditions for the purpose of a dietary supplement for pregnant women 2017.

16. Ovadia YS, Gefel D, Weizmann N, et al. Low lodine Intake from Dairy Foods Despite High Milk lodine Content in Israel. Thyroid. 2018;28(8):1042-51. https://doi.org/10.1089/thy.2017.0654 [published Online First: 2018/06/02].

17. Weaver R, Howells M, Brown H. In: Suite C, editor. IDA Water Security Handbook 2018-2019. Oxford: Media Analytics Ltd; 2019.

18. Proskynitopoulou V, Katsoyiannis IA. Review of recent desalination developments for more efficient drinking water production across the world. New Mater Compd Appl. 2018;2(3):179-95.

19. Ovadia YS, Gefel D, Aharoni D, et al. Can desalinated seawater contribute to iodine-deficiency disorders? An observation and hypothesis. Public Health Nutr. 2016;19(15):2808-17. https://doi.org/10.1017/s1368980016000951 [published Online First: 2016/05/07].

20. Department TINWAP. National Water Efficiency Report: Israeli water Authority. Desalination. 2019

21. Ovadia YS, Gefel D, Turkot S, et al. Elevated serum thyroglobulin and low iodine intake are associated with nontoxic nodular goiter among adults living near the eastern Mediterranean coast. J Thyroid Res. 2014;2014:913672. https://doi.org/10.1155/2014/913672 [published Online First: 2015/01/23]

22. Ma ZF, Skeaff SA. Thyroglobulin as a biomarker of iodine deficiency: a review. Thyroid. 2014;24(8):1195-209. https://doi.org/10.1089/thy.2014.0052 [published Online First: 2014/04/26].

23. Bath SC, Pop VJ, Furmidge-Owen VL, et al. Thyroglobulin as a functional biomarker of iodine status in a cohort study of pregnant women in the United Kingdom. Thyroid. 2017;27(3):426-33.

24. Stinca S, Andersson M, Weibel S, et al. Dried blood spot thyroglobulin as a biomarker of iodine status in pregnant women. J Clin Endocrinol Metab. 2016;102(1):23-32

25. Gefel D, Turkot S, Aharoni D, et al. Serum thyroglobulin levels and estimated iodine intake in adults exposed to iodinediluted desalinated drinking water. Harefuah. 2016;155(8):470-4 [published Online First: 2017/05/23].

26. Benbassat C, Tsvetov G, Schindel B, et al. Assessment of iodine intake in the Israel coastal area. Isr Med Assoc J. 2004;6(2):75-7.
27. Pearce EN, Caldwell KL. Urinary iodine, thyroid function, and thyroglobulin as biomarkers of iodine status. Am J Clin Nutr. 2016;104(Suppl 3):898s-901s. https://doi.org/10.3945/ajcn.115.110395 [published Online First: 2016/08/19].

28. Vejbjerg P, Knudsen $\mathrm{N}$, Perrild $\mathrm{H}$, et al. Estimation of iodine intake from various urinary iodine measurements in population studies. Thyroid. 2009; 19(11):1281-6. https://doi.org/10.1089/thy.2009.0094 [published Online First: 2009/11/06]

29. Health DOMACHDOMAC. Recommendations for supplements during pregnancy and lactation Child Health Department Of Maternal and Child Health. 2017.

30. Zimmermann MB. The effects of iodine deficiency in pregnancy and infancy. Paediatr Perinat Epidemiol. 2012;26(Suppl 1):108-17. https://doi.org/ 10.1111/j.1365-3016.2012.01275.x [published Online First: 2012/07/07].

31. Zimmermann MB, Aeberli I, Andersson $M$, et al. Thyroglobulin is a sensitive measure of both deficient and excess iodine intakes in children and indicates no adverse effects on thyroid function in the UIC range of 100299 mug/L: a UNICEF/ICCIDD study group report. J Clin Endocrinol Metab. 2013;98(3):1271-80. https://doi.org/10.1210/jc.2012-3952 [published Online First: 2013/01/25]

32. Trumbo P, Yates AA, Schlicker $S$, et al. Dietary reference intakes: vitamin A, vitamin $\mathrm{K}$, arsenic, boron, chromium, copper, iodine, iron, manganese, molybdenum, nickel, silicon, vanadium, and zinc. J Am Diet Assoc. 2001; 101 (3):294-301. https://doi.org/10.1016/s0002-8223(01)00078-5 [published Online First: 2001/03/28

33. Rosenthal $\mathrm{E}$, Mates $\mathrm{A}$. lodine concentrations in groundwater of northern Israel and their relation to the occurrence of goiter. Appl Geochem. 1986; 1(5):591-600.

34. Sack J, Kaiserman I, Tulchinsky T, et al. Geographic variation in groundwater iodine and iodine deficiency in Israel, The West Bank and Gaza. J Pediatr Endocrinol Metab. 2000;13(2):185-90. https://doi.org/10.1515/jpem.2000.13.2. 185 [published Online First: 2000/03/11].

35. Gefel D, Turkot S, Aharoni D, et al. Serum thyroglobulin levels and estimated iodine intake in adults exposed to iodine-diluted desalinated drinking water. Harefuah. 2016;155(8):470-4.

36. Tulchinsky TH. Micronutrient deficiency conditions: global health issues. Public Health Rev. 2010;32(1):243.

37. Tulchinsky TH, Kaluski DN, Berry EM. Food fortification and risk group supplementation are vital parts of a comprehensive nutrition policy for prevention of chronic diseases. Eur J Public Health. 2004;14(3):226-8. https:// doi.org/10.1093/eurpub/14.3.226 [published Online First: 2004/09/17].

38. Dary O, Hurrell R. Guidelines on food fortification with micronutrients. Geneva: World Health Organization, Food and Agricultural Organization of the United Nations; 2006.

39. Bouga M, Lean MEJ, Combet E. Contemporary challenges to iodine status and nutrition: the role of foods, dietary recommendations, fortification and supplementation. Proc Nutr Soc. 2018;77(3):302-13. https://doi.org/10.1017/ s0029665118000137 [published Online First: 2018/05/01].

40. Israeli A, Shemer J. It is time to fortify basic foods in Israel according to the Canadian model. Isr Med Assoc J. 2004;6(6):323-5 [published Online First: 2004/06/25].

41. Israel Ministry of Health Boaz Lev M, MHA, Elliot Rosenberg MD MPH Tamy Shohat MM. Healthy Israel 2020. 2011.

42. Hurley S, Eastman CJ, Gallego G. The impact of mandatory iodine fortification and supplementation on pregnant and lactating women in Australia. Asia Pac J Clin Nutr. 2019;28(1):15-22. https://doi.org/10.6133/ apjcn.201903_28(1).0003 [published Online First: 2019/03/22].

43. Dold S, Zimmermann MB, Jukic T, et al. Universal Salt lodization Provides Sufficient Dietary lodine to Achieve Adequate lodine Nutrition during the First 1000 Days: A Cross-Sectional Multicenter Study. J Nutr. 2018;148(4):587-98. https://doi.org/10.1093/jn/nxy015 [published Online First: $2018 / 04 / 17]$

44. Condo D, Huyhn D, Anderson AJ, et al. lodine status of pregnant women in South Australia after mandatory iodine fortification of bread and the recommendation for iodine supplementation. Matern Child Nutr. 2017;13(4). https://doi.org/10.1111/mcn.12410 [published Online First: 2016/12/17].

45. Wang Z, Xing M, Zhu W, et al. lodine Deficiency in Zhejiang Pregnant Women in the Context of Universal Salt lodization Programme. Sci Rep. 2018:8(1):8835. https://doi.org/10.1038/s41598-018-26942-z [published Online First: 2018/06/13].

46. Vargas-Uricoechea $\mathrm{H}$, Pinzon-Fernandez MV, Bastidas-Sanchez BE, et al. lodine Status in the Colombian Population and the Impact of Universal Salt 
Iodization: A Double-Edged Sword? J Nutr Metab. 2019;2019:6239243. https://doi.org/10.1155/2019/6239243 [published Online First: 2019/05/08].

47. World Health Organization. lodine supplementation in pregnant and lactating women 2019 Available from: https://www.who.int/elena/titles/ iodine_pregnancy/en/ Accessed 18 Dec 2019.

48. Andersen SL, Laurberg P. lodine Supplementation in Pregnancy and the Dilemma of Ambiguous Recommendations. Eur Thyroid J. 2016;5(1):35-43. https://doi.org/10.1159/000444254 [published Online First: 2016/04/22].

49. European Food Safety Authority. Scientific opinion on dietary reference values for iodine. EFSA J. 2014;12:3660.

50. Hynes KL, Seal JA, Otahal P, et al. Women Remain at Risk of lodine Deficiency during Pregnancy: The Importance of lodine Supplementation before Conception and Throughout Gestation. Nutrients. 2019;11(1). https://doi.org/10.3390/nu11010172 [published Online First: 2019/01/18].

\section{Publisher's Note}

Springer Nature remains neutral with regard to jurisdictional claims in published maps and institutional affiliations.

Ready to submit your research? Choose BMC and benefit from:

- fast, convenient online submission

- thorough peer review by experienced researchers in your field

- rapid publication on acceptance

- support for research data, including large and complex data types

- gold Open Access which fosters wider collaboration and increased citations

- maximum visibility for your research: over $100 \mathrm{M}$ website views per year

At BMC, research is always in progress.

Learn more biomedcentral.com/submissions 